\title{
Small-scale variations in mining-induced stresses, monitored in a seismically active underground mine
}

\author{
C Dahnér Luleå University of Technology, and Luossavaara-Kiirunavaara Aktiebolag (LKAB), Sweden \\ S Dineva Luleå University of Technology, and Luossavaara-Kiirunavaara Aktiebolag (LKAB), Sweden
}

\begin{abstract}
Kiirunavaara mine, owned by $\angle K A B$, is the largest iron ore underground mine. It is about $4 \mathrm{~km}$ long and has been mined with sublevel caving since the late 1950s. The current mining levels in the main orebody are $1,079 \mathrm{~m}$ and 1,108 $\mathrm{m}$. The sublevel height is $29 \mathrm{~m}$ and it takes about two years to mine one sublevel in the southern half of the mine. As such, the mining-induced stress changes were regarded to be relatively slow. There are 2,700 $M_{w} \geq 0$ seismic events recorded on average every year, with the largest event recorded on 18 May $2020 M_{w} 4.3$.

Not many rock mechanical monitoring campaigns have been undertaken during the mine's history, except for a mine-wide seismic system which has been in operation since 2009. In 2013, 3D stress measurements with the Borre stress cell were undertaken at level 1165 m (production area Block 34), with subsequent installation of $3 D \mathrm{CSIRO}-\mathrm{HI}$ cells for long-term stress change monitoring. The primary purpose of the installation was to measure the changes in the induced stress (magnitude and direction) as the mining progressed downwards. The cell was installed $143 \mathrm{~m}$ below the current production level and at the time of the installation, there were indications that the measured stresses were already affected by the mining-induced stresses. At the time, the local stress state within different production areas was defined only by large-scale generic numerical modelling.

Since the installation, large-scale changes in the induced stresses have been recorded. The current study is focussing on the small-scale variations in the induced stresses which can be related to larger seismic events, development, and production blasting for the time period mid-July 2015 to mid-March 2017. Stress changes before, during, and after 15 seismic events with $m_{L} \geq 1.0$ were analysed. Clear pattern of stress changes for eight events was found. No stress change was observed during 25 development blasts (distance $<50 \mathrm{~m}$ ) and 19 closest productions blasts (125-135 m). Cyclic behaviour of the stress changes was observed with increases starting at 6:00 am which is most probably related to the shift/mucking start at this time. The stress change for a sample of data showed a striking similarity to the seismic activity in the area.
\end{abstract}

The outcome of this work is part of the ongoing project to find patterns/scenarios which will be used for short-term hazard assessment and closing criteria in the mine. The results can be used also for further studies on seismic event preparation processes and co-seismic stresses and deformations.

Keywords: mining-induced stresses, stress monitoring, seismic events, seismic event preparation

\section{Introduction}

The Kiirunavaara mine is the world's largest iron ore underground mine with an orebody $4 \mathrm{~km}$ long, $80 \mathrm{~m}$ wide, and dips $60^{\circ} \mathrm{E}$ (Figure 1a). It started as an open pit mine but has been an underground operation since the 1950s. Since then, sublevel caving has been the dominant mining method except for a short period of sublevel stoping. Sublevel caving is mining the orebody in horizontal slices, starting from the hanging wall and retreating towards the footwall, leaving the hanging wall to cave and fill up the mined-out areas. The mine is divided into 10 production areas, called blocks, along the orebody and numbered according to the $\mathrm{Y}$-coordinate at the centre of each block. This mining method is productive and cost efficient, but it results in 
a redistribution of the stresses with a high stress concentration in the abutments of the cave (Figure $1 \mathrm{~b})$. The current sublevel caving layout is $29 \mathrm{~m}$ level height and $24.75 \mathrm{~m}$ distance between crosscuts.

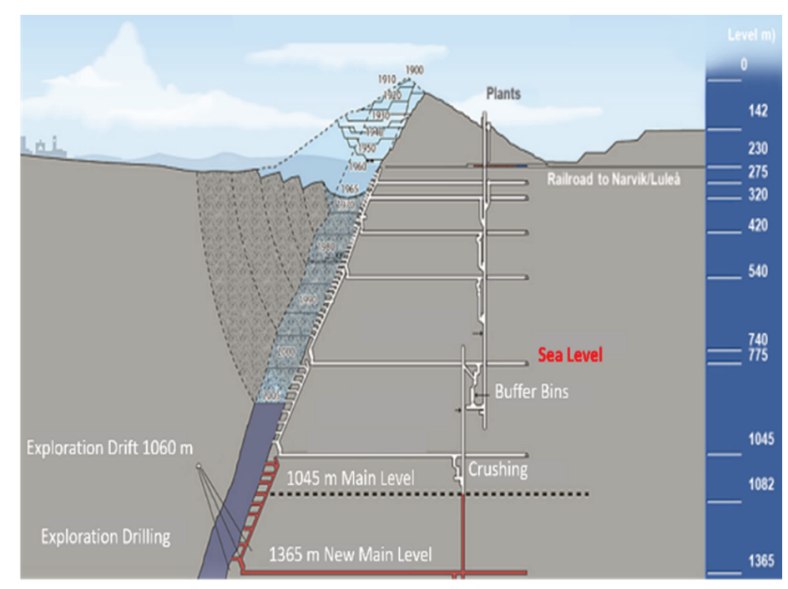

(a)

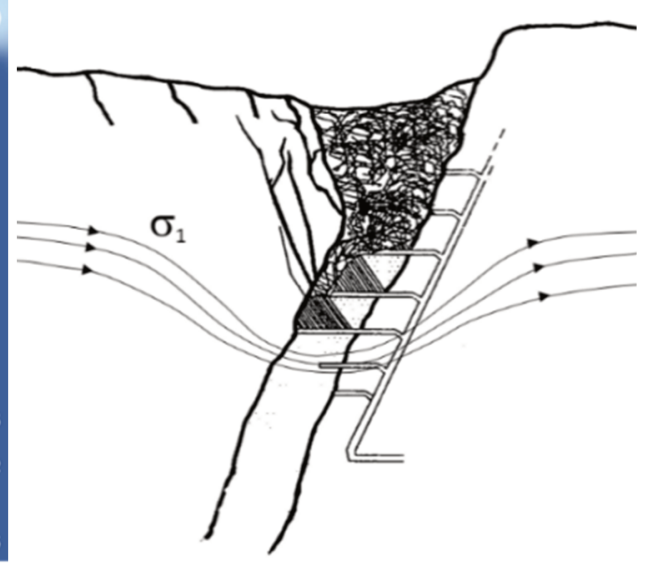

(b)

Figure 1 (a) Cross-section of the mine with the caving hanging wall, ore passes and the hoisting system for the ore to the plants; (b) Schematic cross-section of the mine with the redistributed stresses below production level

As a result of this, the mine turned seismically active and the turning point for the mine came in 2008 . On 2 February 2008, a magnitude 3.0 event took place in Block 19 with extensive damage at three production levels (Sjöberg et al. 2011). During the analyses of this event, it became known that three previous larger seismic events had occurred, one of them in Block 33. This experience initiated, among other things, a mine-wide installation of a seismic system (Dahnér et al. 2012). As the seismic system was installed, it became evident that a large part of the mine was seismically active with focus on Blocks 19, 25, 28 and 33 with the $1045 \mathrm{~m}$ main haulage level system at that time. The corresponding areas in the current $(1365 \mathrm{~m})$ main haulage system are Blocks 22, 26, 30 and 34 . The cause for the larger seismic events has been discussed in length and several approaches were applied in order to understand the mechanism behind them.

In 2012, a project with a focus on explaining the cause for the largest seismic events was started. The project chose to focus on production area Block $33(1045 \mathrm{~m}) / 34(1365 \mathrm{~m})$. The project started with a broad project plan consisting of geotechnical logging and interpretation, numerical modelling, analysis of seismic data and stress measurements/monitoring. The motivation for the in situ stress measurements was that the mine had never measured and monitored changes in the mining-induced stresses. This paper will present and discuss the stress measurements and monitoring data for the selected study period (10 July 2015 - 17 March 2017) with a focus on small-scale changes. In it, we attempt to explain at least some of the small-scale changes that can be related to the time of preparation and occurrence of the larger seismic events, as well as the blasting activities in the vicinity of the stress cell. All analysis was made using various applications of the mXrap software (Harris \& Wesseloo 2015).

\section{Stress measurements and monitoring}

The stress cell at level 1165 was installed on 30 September 2013. At that time, production was ongoing at levels $993 \mathrm{~m}$ and $1022 \mathrm{~m}, 143 \mathrm{~m}$ above the measurement site (Figure 2). The stress measurement method was overcoring with the Borre stress cell (Sjöberg et al. 2003). The results (Ask 2013) are presented in Table 1.

For comparison, the empirical formula derived by Sandström (2003) for the virgin stresses increase with depth gives $43 \mathrm{MPa}$ for $\sigma_{\mathrm{EW}}, 33.7$ for $\sigma_{\mathrm{V}}$ and 32.5 for $\sigma_{\mathrm{Ns}}$. Taking into account that $\sigma_{1}$ is almost in the EW direction, we can conclude that at the time of the measurements, the local stresses were already $22.5 \mathrm{MPa}$ (or 1.5 times) larger than the virgin stresses. 


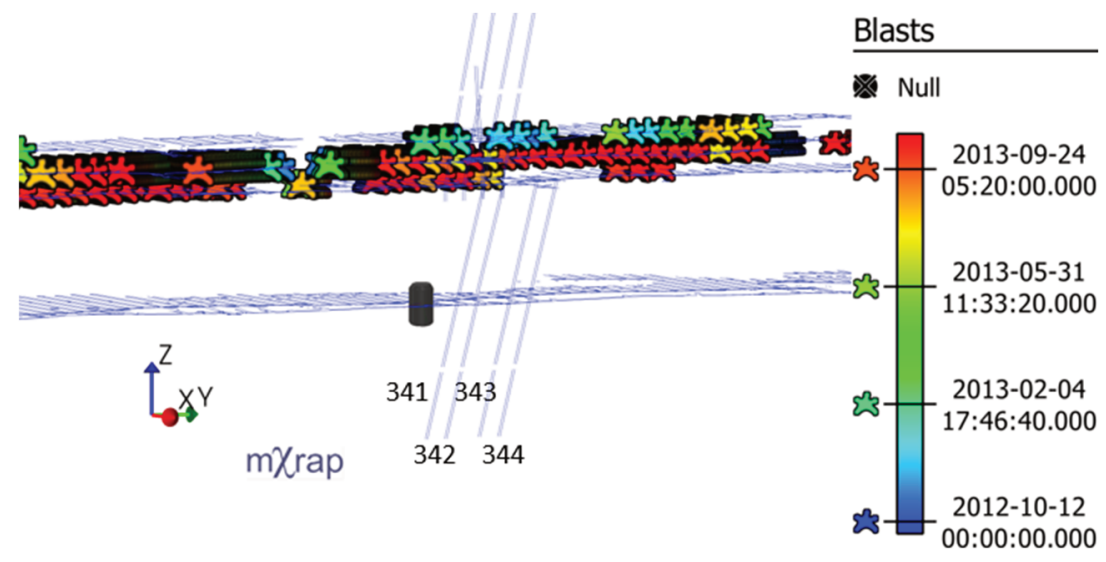

Figure 2 The location of the stress cell (purple cylinder) at drift 1,165 $\mathrm{m}$ with one year of production blasts up to the date for the stress measurements and installation of the monitoring cell. The ore passes nearby (inclined lines) are shown with their numbers

Table 1 Measured absolute stresses at level 1165, 30 September 2013 (Ask 2013)

\begin{tabular}{lll}
\hline Stress component & Stress magnitude (MPa) & Stress strike/dip (geographical north) \\
\hline$\sigma_{1}$ & 65.5 & $089 / 16$ \\
$\sigma_{2}$ & 42.6 & $187 / 26$ \\
$\sigma_{3}$ & 26.8 & $331 / 59$ \\
\hline
\end{tabular}

After the stress measurements, 3D CSIRO-HI cells were installed for long-term monitoring with data sampling every 15 minutes. The time interval was chosen to not be too small, therefore avoiding introducing heat to the glue around the cell, but small enough so we would be able to capture short-term variations.

The monitoring period analysed and discussed in this paper is 10 July 2015-17 March 2017. The changes in mining-induced stresses $\left(\sigma_{1}, \sigma_{2}\right.$ and $\left.\sigma_{3}\right)$ over the study period are presented in (Figure 3$)$. For the total stress values, the initial measured stresses need to be added to the data in the graph. The $\sigma_{1}$ direction (red colour) is the component that has increased most. Based on a visual inspection, the measurement accuracy between individual recordings is estimated to be $\pm 0.1 \mathrm{MPa}$ (the insert). It should be noted that the data series have some short interruptions in the recordings due to data collection problems. The work presented in this paper focusses on short-term changes in the stresses. The long-term effects of glue hardening and the effect of temperature changes between seasons have not been studied at this stage.

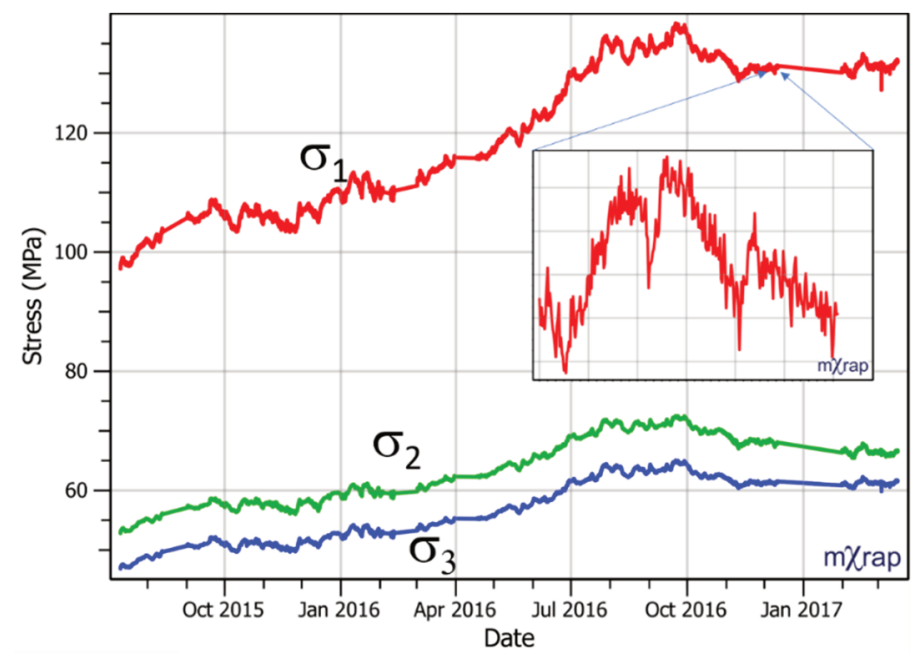

Figure 3 Principal stresses $\sigma_{1}, \sigma_{2}, \sigma_{3}$ over the study period 10 July 2015-17 March 2017 with a zoom-in to show the variations in individual recordings 


\section{$3 \quad$ Analyses and results}

All following analyses are done by visual inspection of the graphs of the monitored mining-induced $\sigma_{1}$ stress. Only this component was analysed as the changes are larger and more pronounced in it. We have chosen to evaluate the stress changes versus:

- Development blasts in the vicinity of the stress monitoring cell.

- Production blasts in the vicinity of the stress monitoring cell.

- Larger seismic events in the vicinity of the stress monitoring cell.

- Production/loading in ore passes.

\subsection{Stress response to development blasts}

During the chosen time period, 25 recorded development blasts took place within a $50 \mathrm{~m}$ radius from the stress cell (Figure 4). The blasts were located at levels $1137 \mathrm{~m}$ and $1165 \mathrm{~m}$. The $50 \mathrm{~m}$ radius was chosen as a starting point. If a response on the monitored mining-induced stresses was detected, the study volume would have been increased until no response could be detected. For each individual blast, the seismic response and the stress response has been evaluated. For all 25 blasts, a sphere of $100 \mathrm{~m}$ radius was placed around the stress blast to capture any possible corresponding/induced seismic activity. This was regarded as extreme, but it took into account possible events with large location errors. In Figure 5, two examples of the behaviour of the mining-induced stresses are shown. Figure $5 a$ is an example of a blast which resulted in no visible response on the monitored induced stresses and no seismic activity. Figure $5 b$ is an example of an ambiguous case with a very weak and questionable response on the monitored stress and weak corresponding seismic activity.

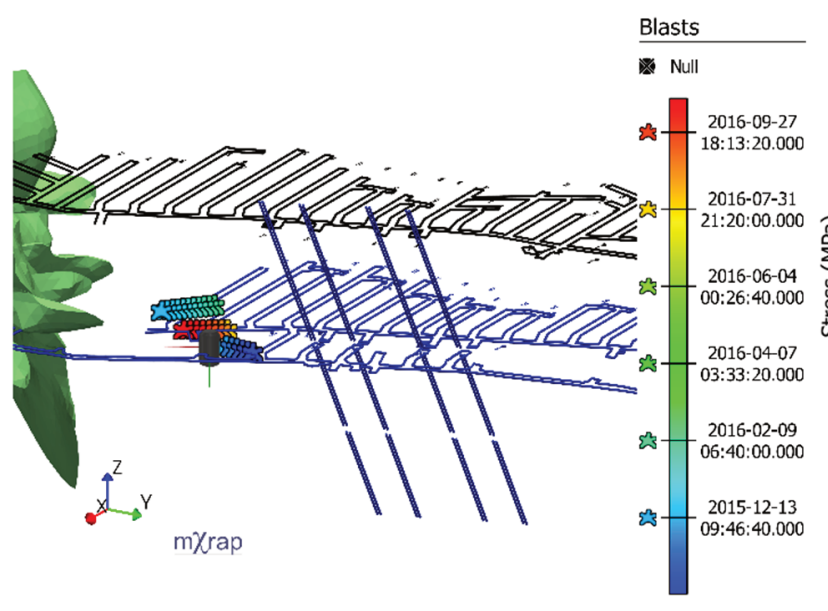

(a)

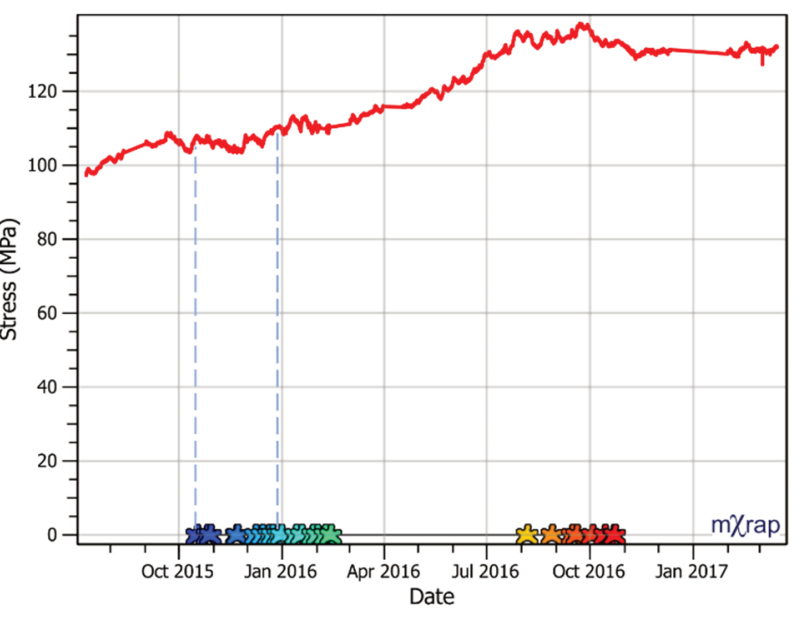

(b)

Figure 4 (a) The stress cell (cylinder) and the 25 recorded development blasts within a $50 \mathrm{~m}$ sphere; (b) Principal stress $\left(\sigma_{1}\right)$ and the time of the blasts (stars). All blasts (stars) are with colour depending on the time (see the legend) 


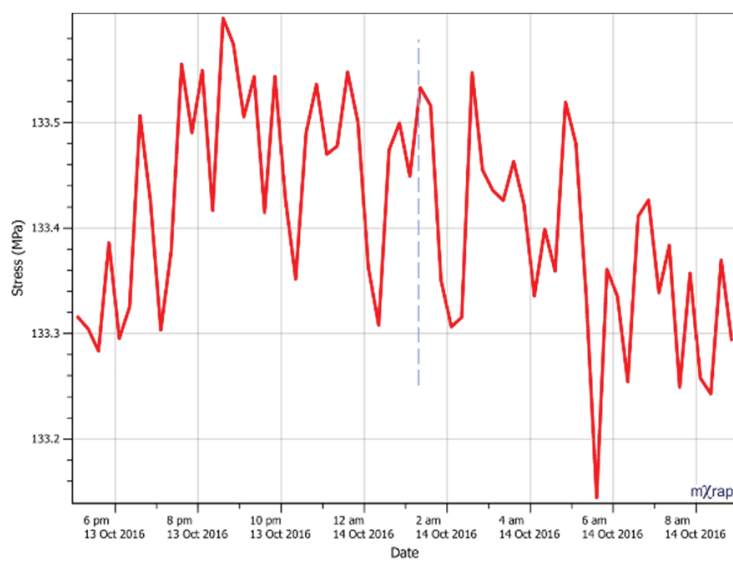

(a)

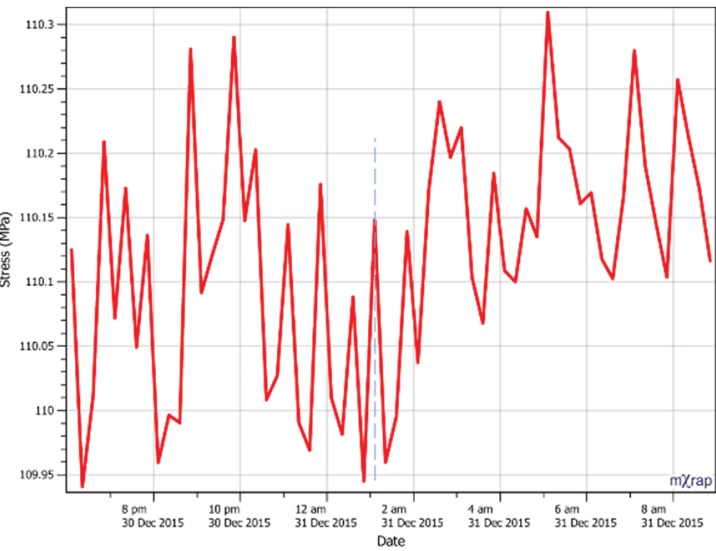

(b)

Figure 5 (a) The stress reaction to a development blast on 14 October 2016 at 01:15; (b) The stress reaction to a development blast on 31 December 2015 at 01:15

The following result was obtained for the 25 development analysed blasts (Table 2).

Table 2 Summary of the results of the 25 analysed development blasts

\begin{tabular}{ll}
\hline Stress response & Number \\
\hline Blasts with corresponding stress data - no clear response & 21 \\
Blasts with corresponding stress data - ambiguous response & 2 \\
Blasts without corresponding stress data - possibly error in the production database & 2 \\
\hline
\end{tabular}

A conclusion was made that the development blasts within $50 \mathrm{~m}$ do not affect the static stresses to any degree of concern. The dynamic stress changes caused by the seismic waves passing through the rock mass are not visible as the sampling frequency of 15 minutes is not enough to capture this phenomenon.

\subsection{Stress response to production blasts}

The closest production blasts to the stress cell were at distance $125-135 \mathrm{~m}$. Within a sphere with radius $135 \mathrm{~m}, 19$ production blasts were in the study period (Figure 6). All of them were at production level $1051 \mathrm{~m}$.

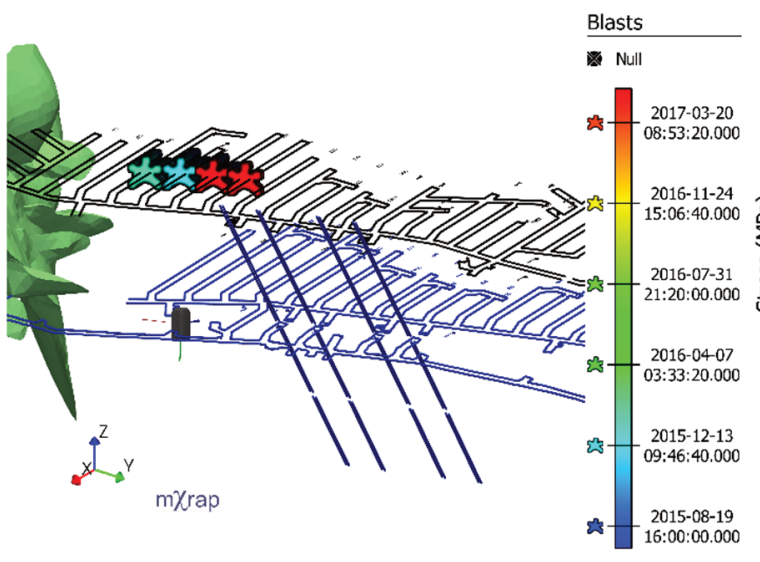

(a)

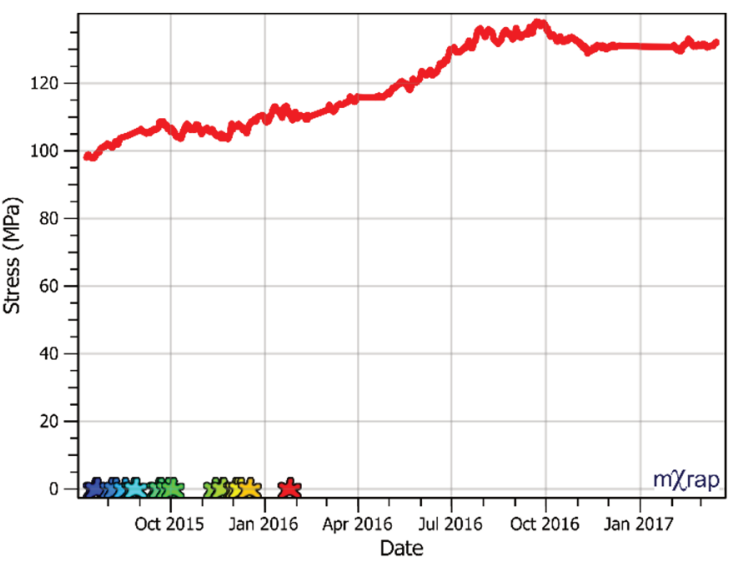

(b)

Figure 6 (a) The stress cell (cylinder) and the 19 production blasts within a $135 \mathrm{~m}$ sphere, green isosurface representing a clay zone; b) Principal stress $\left(\sigma_{1}\right)$ and the time of the blasts (stars). All blasts (stars) are with colour depending on the time (see the legend) 
Two examples of stress and seismic response to production blasting are presented, as illustrated in Figure 7. First, production blast with a weak seismic response is shown in Figures $7 \mathrm{a}$ and $7 \mathrm{~b}$. As it is obvious at the time of the blast, the stress changes are in the order of standard deviations and no indication for any change due to the blast. On the other hand, a small trend of increasing stress was observed at about 06:00. This time corresponded to shift start in the mine (the purple line in Figure 7a). The effect of the shift starts (mucking) is discussed further in Section 3.4. Secondly, the reaction to three simultaneous production blasts is presented in Figure $7 c$ with the post-blast seismicity in Figure $7 \mathrm{~d}$. It seems that the overall seismic response was stronger than in the previous case, but there was no indication on the stress monitoring data that the stresses were affected by these three production blasts. There was no effect on the stress cell data from the post-blast seismicity either.

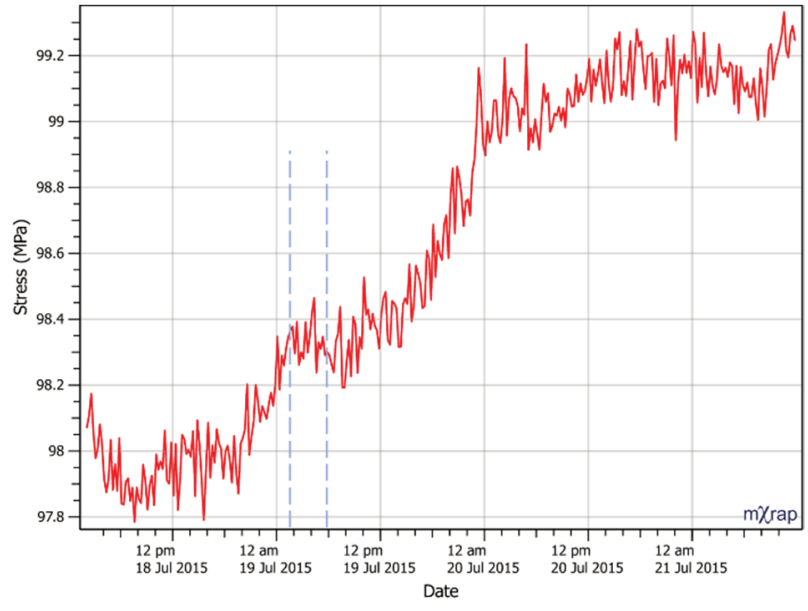

(a)

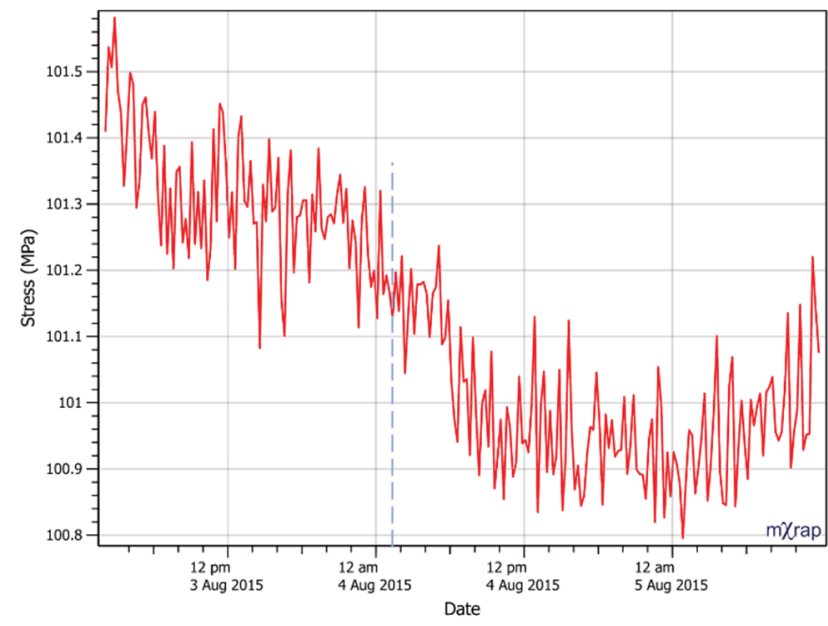

(c)

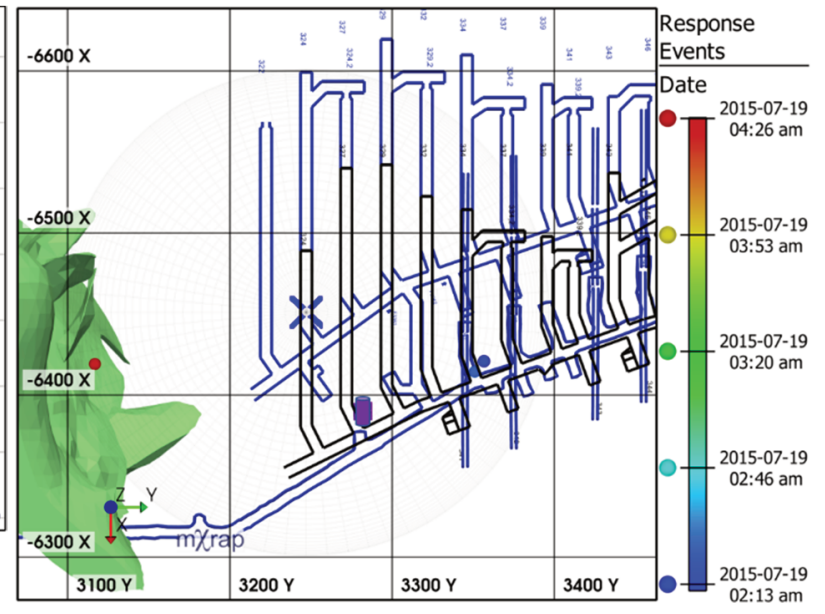

(b)

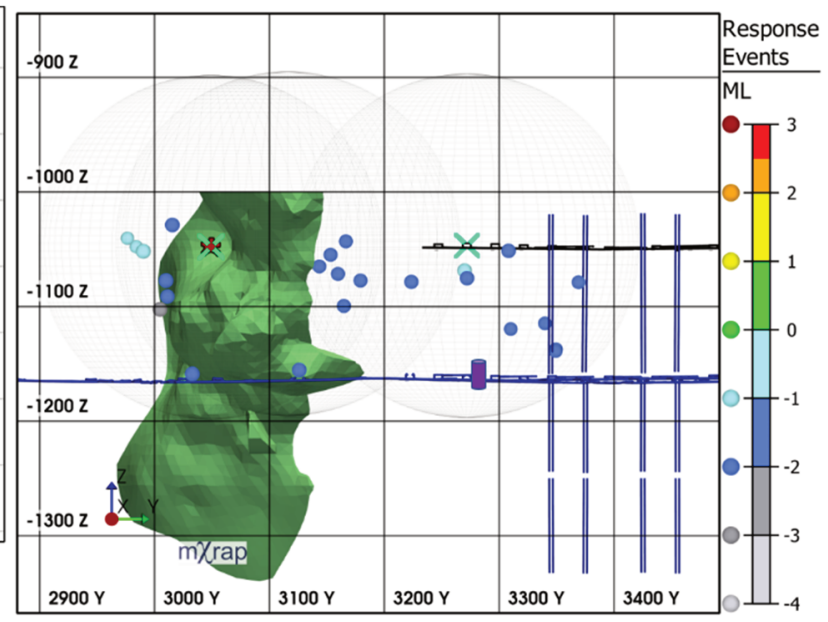

(d)

Figure 7 Behaviour of the monitored stresses at the time of two production blasts $(a, c)$ and the seismic response to blasting $(b, d)$ with production blasts marked as coloured $x$ and a clay zone marked as a green isosurface. Blasts: (a, b) 19 July 2015 at 01:29, (c, d) 4 August 2015 at 01:34 - three simultaneous blasts. The seismic response from the production blasts in the first four hours was within a sphere with $150 \mathrm{~m}$ radius. The blue lines on (a) and (c) correspond to the time of the blast. The purple line is the time when the mucking started

In Table 3, a summary of the results from the analyses of the 19 production blasts is presented. For the closest 19 production blasts to the stress cell, no changes in the static stress field could be confirmed. 
Table 3 Summary of the results of the 19 analysed production blasts

\begin{tabular}{ll}
\hline Stress response & Number \\
\hline Blasts with corresponding stress data -no clear response & 14 \\
Blasts with corresponding stress data -clear response & 0 \\
Blasts without corresponding stress data & 5 \\
\hline
\end{tabular}

\subsection{Stress response to seismic events}

For the analyses of a possible correlation with larger seismic events, a dataset with seismic events with $M>1.0$ within a radius of $150 \mathrm{~m}$ from the stress cell and for the study period was created. In total, there were 14 seismic events with $1.01<M<1.91$. Each event has an identity number which will be referred to in the discussions (Figure 8).

The dataset can be divided into two subgroups-ore pass events (nine events) and clay zone related events (five events)-out of which one event is regarded as blast-induced (number 7). After going through the methodology described below, it was intended to investigate if any larger events had occurred just outside the selection volume which would have a very large aftershock volume and could therefore be related to possible responses in the stress cell. One event was found (number 15).

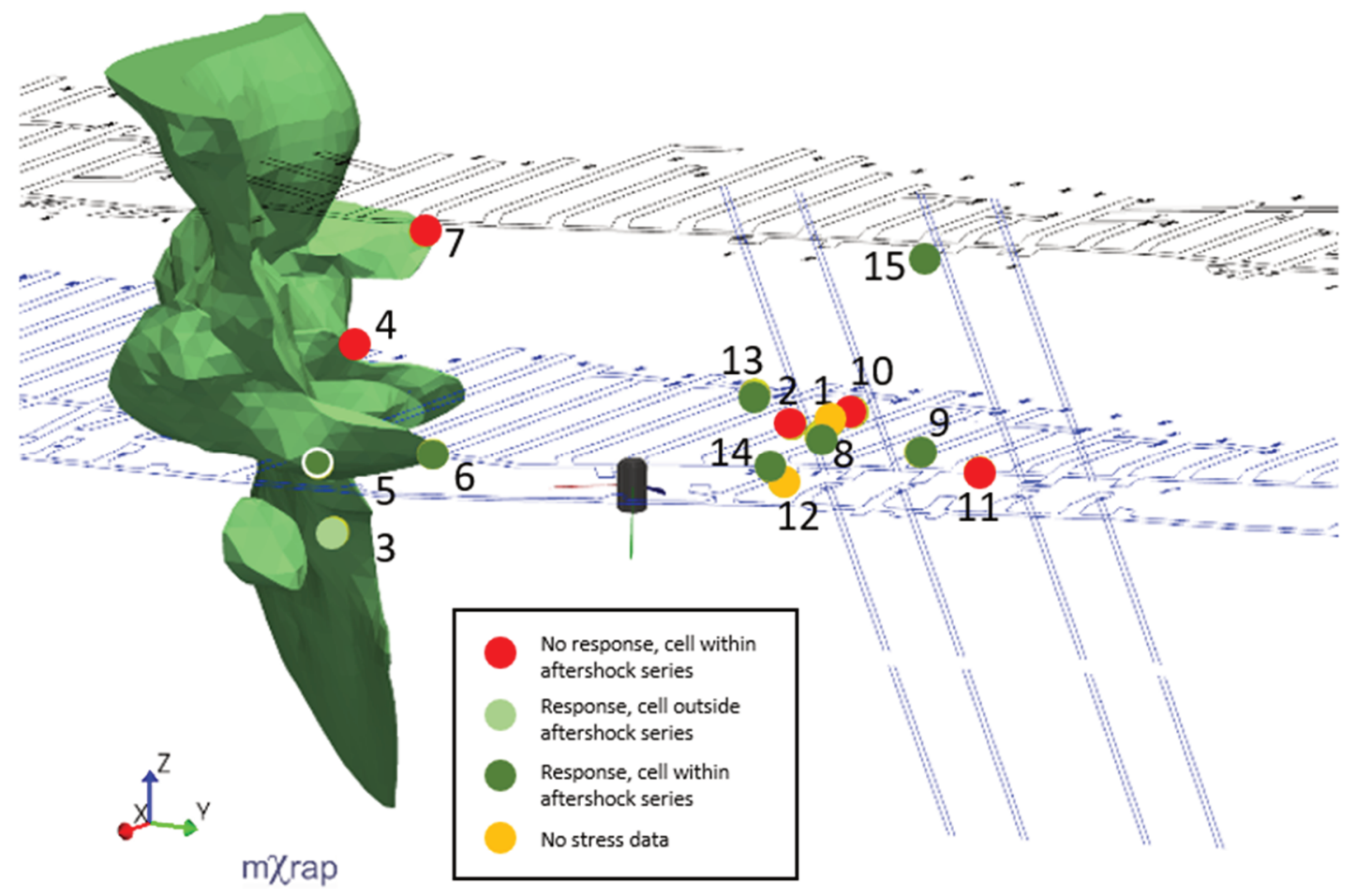

Figure 8 Seismic events $M>1.0$ within $150 \mathrm{~m}$ radius from the stress cell. Black infrastructure corresponds to current production level $(1051 \mathrm{~m})$ and blue corresponds to future production level and media drift at level $1165 \mathrm{~m}$. Sub-vertical lines are ore passes in group 34 and the green volume is a clay zone. The circles with corresponding numbers are the location of the large events in the analysis with colour as in the legend

The methodology for this analysis was:

- Make a table of the events with time, location, magnitude and calculated source radius.

- Calculate the distance between each seismic event location and the stress cell location. 
- For each event, analyse the aftershock volume and time with the 'Short-Term Response Analysis' app in mXrap.

- Complete the table with the radius of the aftershock volume. This volume is now regarded as the new seismic source size.

- See if the stress cell location is within the new seismic source size.

- Analyse the graph of the monitored induced stress changes with the help of the 'Stress Cell' app in $m X r a p$ and look at the behaviour before, during, and after the seismic event. Determine if:

- There is an increase in the stresses before and after the seismic event, regarded as a response, and if there is a pattern in the responses.

- There is no clear pattern or a decrease in the stresses before and after the seismic event, regarded as no response.

- Measure the changes of the mining-induced stress in time and magnitude before, during, and after the seismic event.

Some examples of different seismic events with aftershocks and corresponding response on the monitored induced stresses are shown in Figure 9. In Figure 9a, we have two events (numbers 5 and 6) occurring close in time and within the same increase of the induced stresses with their aftershocks in Figure 9b. In Figure 9c, there is a main event (number 8 ) and an aftershock within the same minute. The aftershock series of the events in shown in Figure 9d. In both cases, there is an increase in the induced stresses after a period of decrease. In the first case, the period of decrease is around seven days (168 hours) ( $t_{1}$ on Figure 10), followed by an increase before the event at around 45 hours $\left(t_{2}\right)$. The amplitude of the decrease $\left(a_{1}\right)$ was $3 \mathrm{MPa}$, and of the increase $\left(a_{2}\right) 1.6$ and $2.4 \mathrm{MPa}$ for the first and second events. In the second case, the increase in the beginning $\left(t_{1}\right)$ continues for 104.5 hours, followed by an increase $\left(t_{2}\right)$ for 24 hours. The amplitudes of the stress change $\left(a_{1}\right.$ and $\left.a_{2}\right)$ were $4 \mathrm{MPa}$ and $0.5 \mathrm{MPa}$, respectively. After the seismic events, the stress continued to increase for a while. In the first case, the increase from the minimum $\left(t_{3}\right)$ continued for 360 hours and in the second one for 162 hours. The total increase $\left(a_{3}\right)$ was 5.5 and $3.5 \mathrm{MPa}$, respectively.

In Figure 9e, there is also a case where there was no clear response in the monitored induced stresses before and after the event. The aftershock series is shown in Figure $9 f$. In all three cases, the stress cell was inside the volume with the aftershocks.

For the events for which a stress change was observed, there was a clear pattern in the behaviour (Figure 10). After a period of decrease, the stress starts increasing until the seismic events occurs and after this, continues increasing for a while. The amplitude of the variations is much larger than the measurement accuracy $( \pm 0.1 \mathrm{MPa})$. 


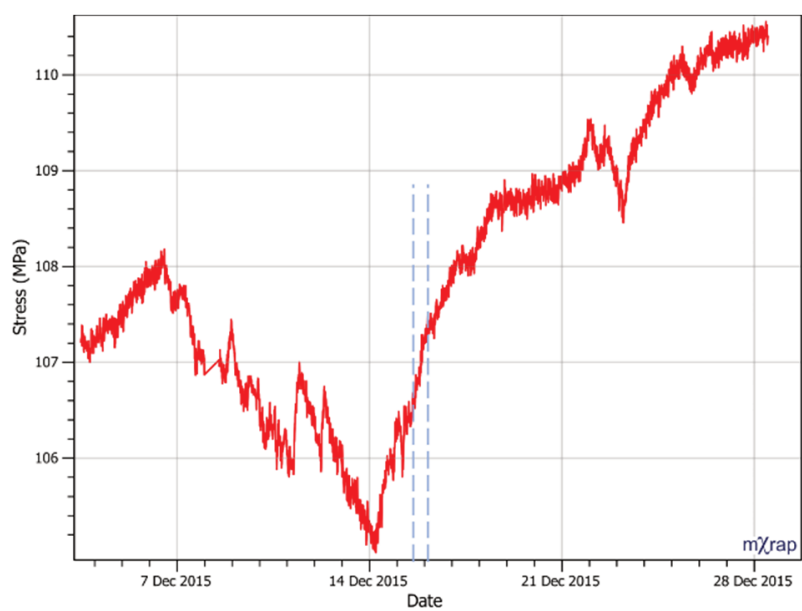

(a)

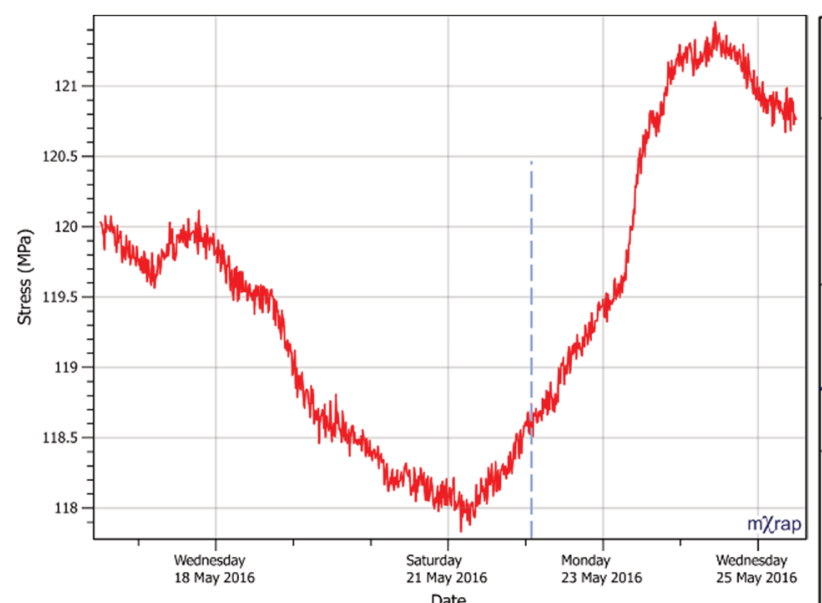

(c)

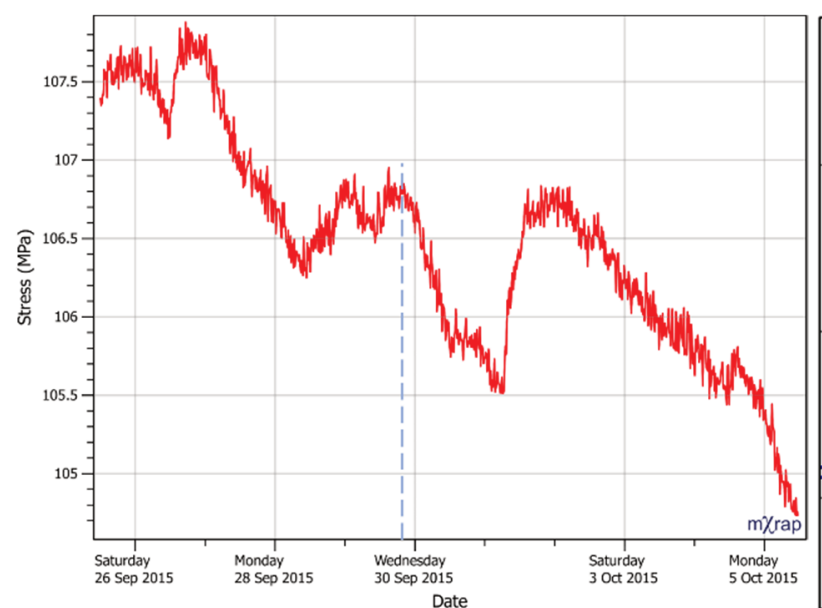

(e)

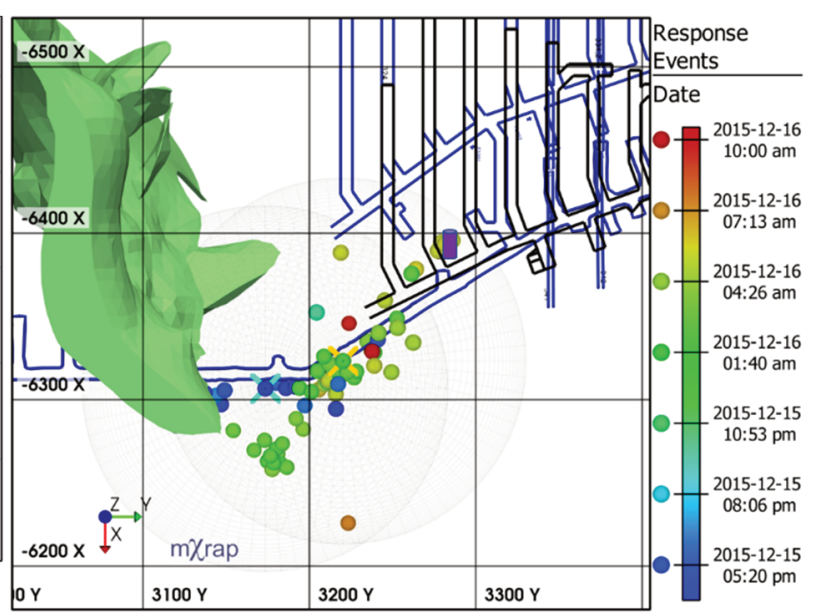

(b)

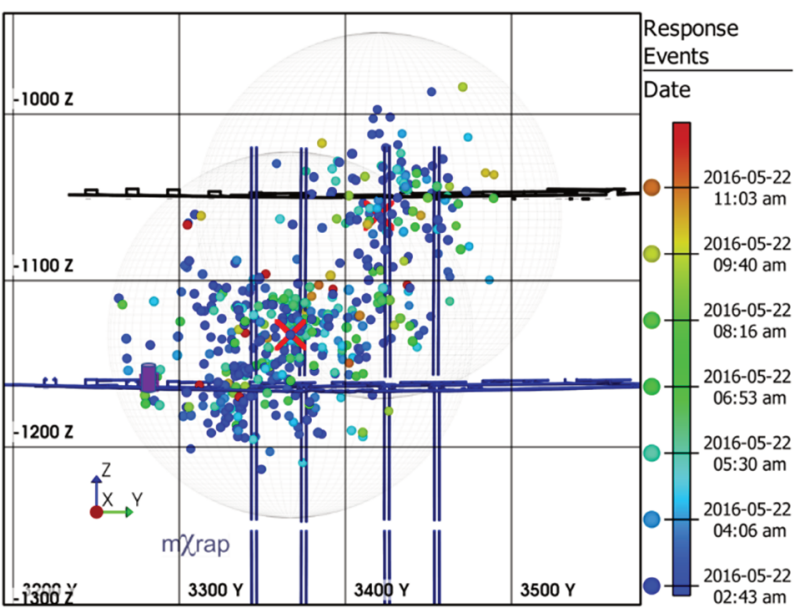

(d)

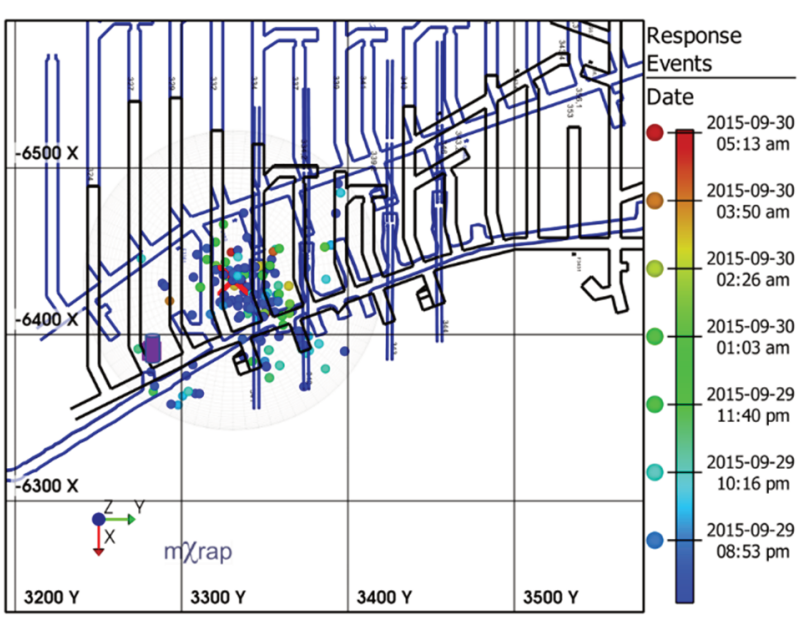

(f)

Figure 9 (a) Stress response at the time of large events (left) and aftershock series for the events (right): (a, b) 15 December 2015 at 15:57 and 16 December 2015 at 02:52 (events 5, 6), (c, d) 22 May 2016 at 02:31 (event 8), (e, f) 29 September 2015 at 19:36 (event 2). Time of the events is shown as a blue dashed line 


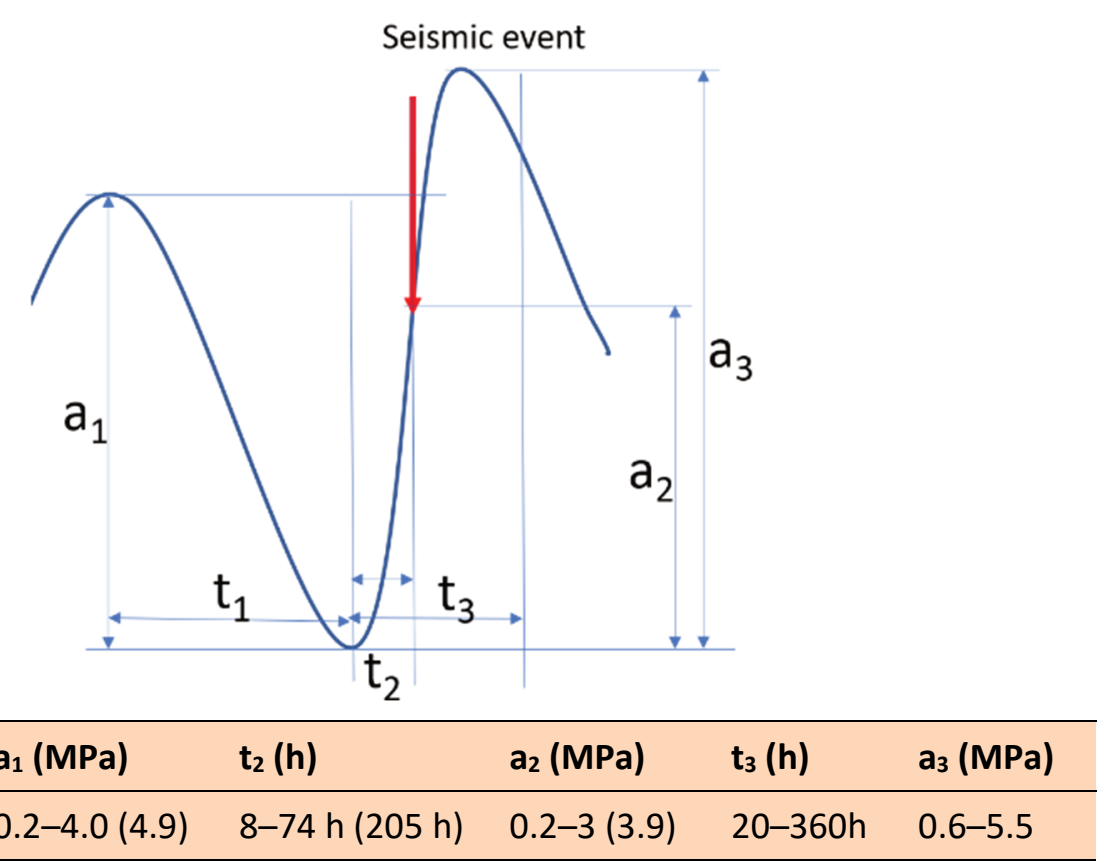

Figure 10 Pattern of the mining-induced stresses before, during, and after the seismic event occurs. (a) Definitions; (b) Range of the parameters of the pattern (min-max (extreme values))

The result from the analysis of the 14 seismic events with $M>1.0$ occurring within $150 \mathrm{~m}$ from the stress cell (and an additional event no 15 at distance $190 \mathrm{~m}$ ) and within the study period is shown in Figure 11 . Out of the 15 events, we can see a clear increase in stresses before the seismic event takes place in eight cases, all marked with green arrows. Unfortunately, for two seismic events (yellow arrows), there is no recorded stress data. One of the events (number 7) is classified as a production blast induced event and it occurred at a peak in the stress monitoring curve (red arrow). For the four remaining events, there is no typical change in the stresses corresponding to the time before/after their occurrence (red arrows).

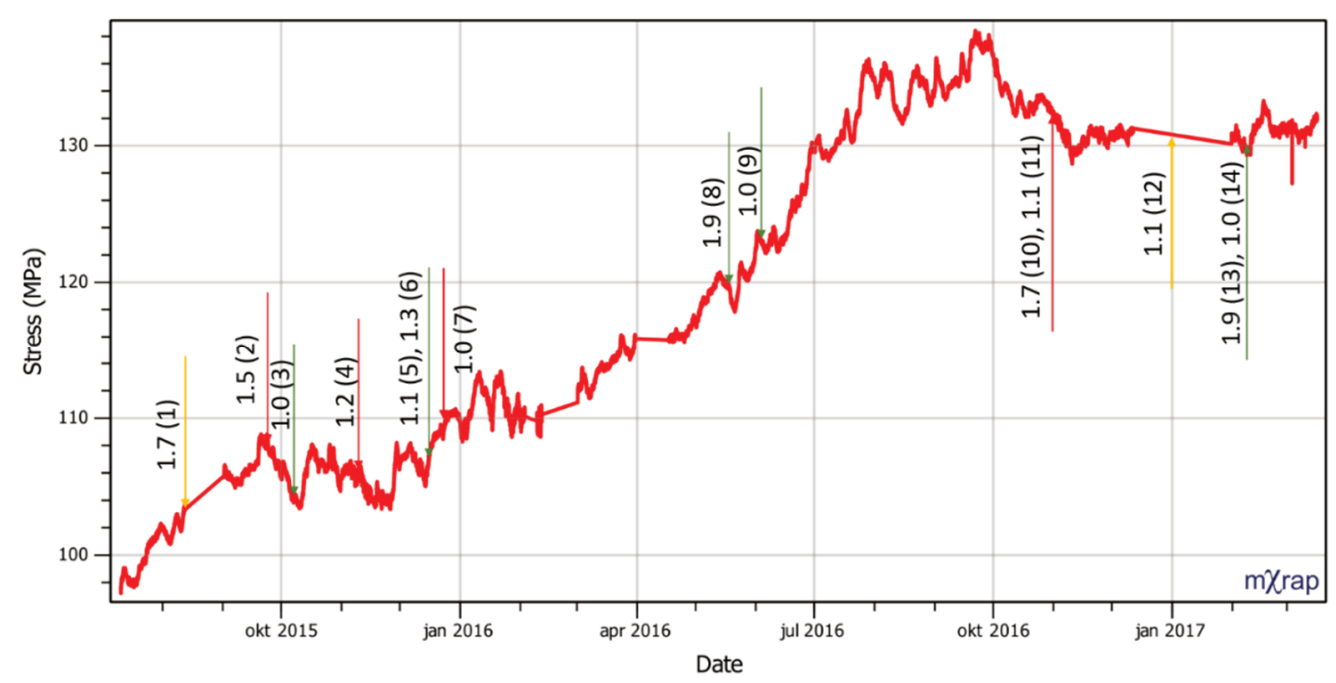

Figure 11 The monitored induced $\sigma_{1}$ stresses for the study period with arrows for each analysed seismic event with $M>1$; green arrow (seismic event correlates with increase in stresses), yellow arrow (no stress cell data), red arrow (no typical change). Number of the events corresponds to the number in Figure 8

\subsection{Stress response to production/loading in ore passes}

When observing the monitored induced stress graph, it became obvious that during certain periods, it exhibits a cyclic behaviour running over consecutive days starting around 06:00. As the shift in the mine starts 
at 06:00, this is an indication that the pattern of the stresses is related to other production activities than blasting in the area. Looking closer at the seismic activity in the neighbourhood of the stress cell, the dominant activity is related to mucking in orepass 343 which is at about $170 \mathrm{~m}$ from the stress cell. In this mine, the blasted ore is loaded semi-continuously into ore passes during morning and afternoon shifts. The ore passes are emptied 24/7 at the bottom into trains. During the night shift, the level of the ore could drop. The ore pass original diameter is $3 \mathrm{~m}$ but as it is used, it wears and grows, sometimes up to about $40 \mathrm{~m}$. The mine tries to keep a high level of the ore in the ore passes to prevent further growth.

In Figure 12a, we present the stress cell data and in Figure 12b, the seismic activity in time for the period 1 January 2016-10 January 2016 as an example. The seismic activity is within a 400 m cube with the stress cell at the centre. The seismic activity is shown as individual events and as cumulative number of events. There is a striking similarity between the two graphs for this time period, especially for the second half. Seismic activity is also shown as individual events on a vertical plane. It is obvious that this activity is mostly around orepass 343 . This observation suggests that to a large extent, the processes in the ore passes might be causing the stress change monitored by the stress cell.

The cyclic behaviour in the monitored stresses have been observed for several time periods but no evaluation with the seismic activity related to production activities for any other time period has been made as this was not the main focus for the paper.

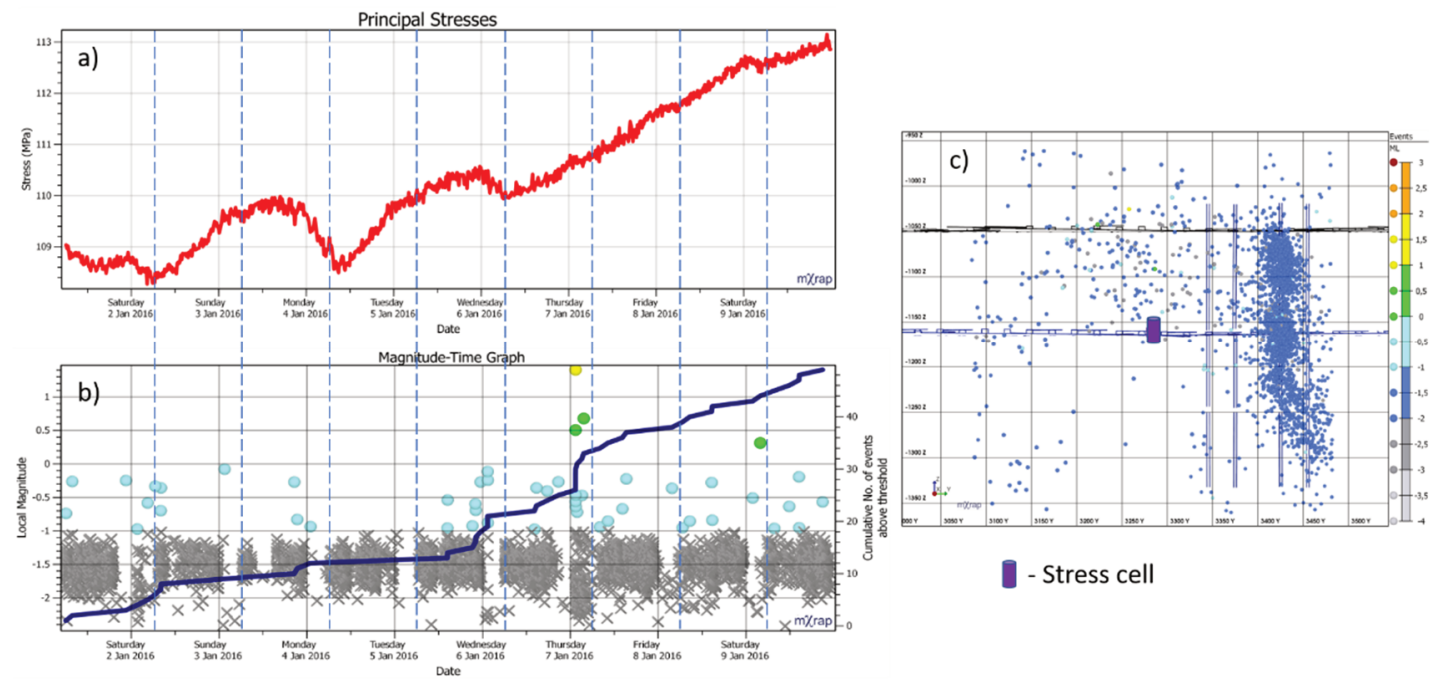

Figure 12 (a) The monitored induced stresses for the period 1-10 January 2016; (b) Individual seismic events and cumulative number in time; (c) A vertical section of seismic event locations within $\mathbf{4 0 0} \mathrm{m}$ around the stress cell. The blue vertical dashed lines correspond to start of the production in the area

\section{$4 \quad$ Discussions and conclusions}

This paper presents the recordings of changing mining-induced stresses over the time period 10 July 2015-17 March 2017 at one location on level 1165 in Block 34. Although the monitored changes in the stresses were large over the time period ( $40 \mathrm{MPa})$, an attempt was made here to explain some of the short-term, small-scale changes.

When analysing the response of the stresses to the development blasts (distance $<50 \mathrm{~m}$ ) and production blasts (distance 125-135 m), no indication of an increase/decrease in the static stresses due to individual blasts could be verified, not even for cases when multiple production blasts took place at the same time and next to each other.

The analysis of the behaviour of the stress before, during, and after 15 seismic events with $M>1$ at distance up to $150 \mathrm{~m}(190 \mathrm{~m})$ showed that the occurrence of eight of the events can be correlated with the stress change behaviour. The changes in the stress show an almost clear pattern; a clear drop in the stress 
magnitude followed by an increase before the event occurs and a continuing increase after the event, before it starts decreasing again. This pattern for events was found when the stress cell was both within the aftershock volume, as well as outside. The stress change (drop/increase) varies from event to event but it is no larger than 5-5.5 MPa. The corresponding time intervals also vary. The stress decrease interval could be as long as 468 hours ( 19.5 days) and the time interval of the increase before the seismic event is up to 205 hours (8.5 days). Unfortunately, there is no stress data for the time of two seismic events, and for five events, no pattern was observed. No correlation was found between the spatial distribution of the seismic events with clear stress response and no response. It is possible that the focal mechanism of the events played a role in the reaction of the stress cell. This problem needs further study. We also observed at least 18 occasions when the stress increases and drops afterwards for which we don't have any clear explanation. This needs to be studied further.

When looking in more detail at the aftershocks from three of the events $(3,5$ and 6$)$ related to the clay zone area, they all form a plane ( $180 \mathrm{~m}$ long) together with their aftershocks (Figure 13). The three events occurred within two months. For two of these events ( 3 and 5$)$, both the seismic source and the aftershock radii are smaller than the distance between the seismic event and the stress cell. For all three events, a stress change pattern was identified. If it is assumed that this plane is a geological feature that started to fail, it is likely that stresses were building up in a large volume and released as separate events. This would explain the observed response in the stress changes even when the stress cell was beyond the aftershock volume. This result was interpreted as a clear indication of stress changes related to larger seismic events and a continuous increase in stresses for a period of time, followed by decrease only after the whole cycle had finished.

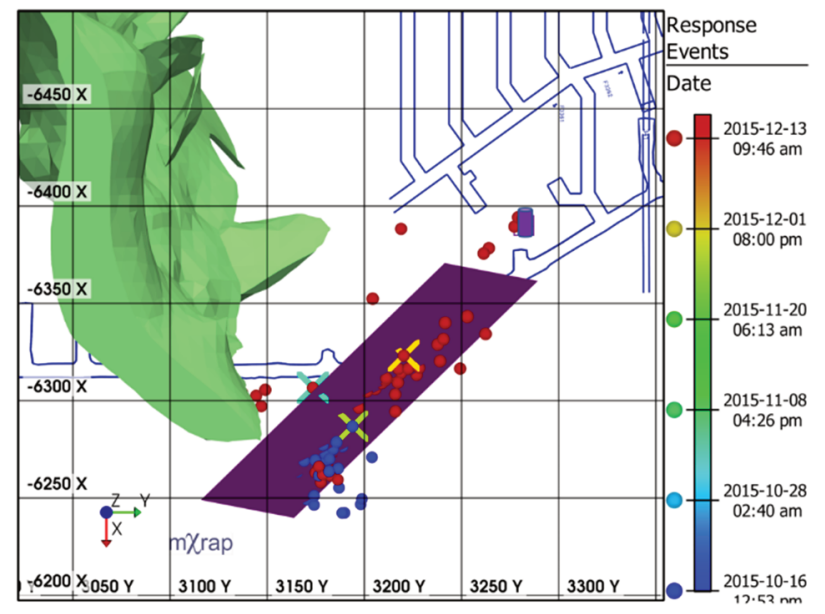

(a)

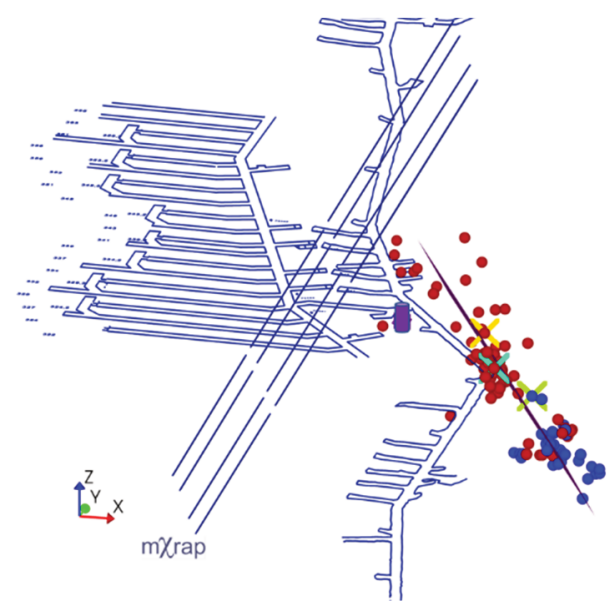

(b)

Figure 13 The interpreted plane from aftershock sequences from events 3,5 and 6 . Each main event is marked with a coloured $X$, and the aftershocks are coloured by time of occurrence. (a) Plan view; (b) Isometric view facing south/down

There were cases for which an identified pattern was not detected (red events). There can be several reasons for this. The geometry of the failure plane relative to the stress cell location could be unfavourably oriented with the stress cell in a stress shadow. Three of the red seismic events are related to the ore pass area, e.g. ore pass events. These events were likely to be related to the rock mass degradation and failing around the ore passes, causing them to grow. The seismic moment tensor for these events has not been studied yet but it is of interest to calculate it for all events and see if there is a difference in stress response depending on the source mechanism (fault slip events versus pillar burst). It will also be interesting to see if there is a difference in the preparation phase for these two types of events regarding the volume of preparation and the magnitude of the stress change before a fault slip event versus a pillar failure/ore pass collapse event.

During the analysis, a cyclic behaviour in the monitored stress data was detected for several time periods. Although not within the scope of this paper, one time series of stress change data was presented, together 
with the seismic activity in the area. A remarkable resemblance between the two curves was found. The seismic activity for this period was related to mucking in ore pass 343 , about $170 \mathrm{~m}$ from the stress cell. Between the stress cell and this ore pass, two other ore passes (341 and 342 ) are situated. Both have grown substantially in size and 341 was even permanently closed for production. This led to the question: how big is the volume of rock that this kind of instrumentation can be expected to represent? Or maybe the question should be posed the other way around: how big is the volume of the rock mass that undergoes stress changes around an ore pass in production?

There are some more short period changes in the stress magnitude that have not been explained yet.

\section{$5 \quad$ Future work}

This analysis is only the first glance at the stress data collected in almost seven years. The work was planned to continue in different directions to take full advantage of the rare occasion of a long experimental data sequence in an active mining area. Ideas for further studies include: 1) Relation between the short-term stress response and the moment tensor of the large seismic events, magnitude and distance to the cell; 2) Correlation between the long-term stress changes and seismicity in the volume around the stress cell; 3) Explain the short period changes in the stress magnitude that have not been explained yet; 4) Long-term effects of glue hardening, seasonal temperature and atmosphere pressure variations on the stress variations; 5) Correlation between the production (mining front geometry) and the long-term stress changes; 6) Detailed analysis of the stress changes in relation with the orepass processes (experimental data versus numerical modelling); and 7) Design a plan for instrumentation of the whole mine using the experience gained from the analysis of existing data.

\section{Acknowledgements}

All analysis in the paper is made with various apps in mXrap software. An experimental app (stress cells) included in the incubator was developed by Kyle Woodward (Australian Centre for Geomechanics). We thank him for his hard work to make it happen. Biruk Woldemedhin and Erik Swedberg (LKAB) were very helpful with collecting the data and making the first analysis. The project was initially funded by LKAB. The recent development was funded by the strategic innovation program SIP STRIM (project No 2016-02629), a joint venture by Vinnova, Formas, and Energy Agency (Sweden), and by LKAB.

\section{References}

Ask, D 2013, Bergspänningsmätningar med Borre och spänningsmonitering med CSIRO HID i block 34, nivå KUJ1070, KUJ1165, och KUJ1252 (Rock stress measurements with Borre and stress monitoring with CSIRO HID in Block 34, level KUJ1070, KUJ1165, and KUJ1252), Pöyry internal report no. 8H50124.130 Pöyry, Vantaa.

Dahnér, C, Malmgren, L \& Boškovic, M 2012, 'Transition from non-seismic mine to a seismically active mine: Kiirunavaara Mine', Proceedings of the ISRM International Symposium-EUROCK 2012, International Society for Rock Mechanics and Rock Engineering, Lisbon.

Harris, P \& Wesseloo, J 2015, mXrap, computer software, Australian Centre for Geomechanics, The University of Western Australia, Perth, www.mxrap.com

Sandström, D 2003, Analysis of the virgin state of stress at the Kiirunavaara mine, Licentiate thesis, Luleå University of Technology, Luleå.

Sjöberg, J, Christiansson, R \& Hudson, JA 2003, 'ISRM Suggested Methods for Rock stress estimation-Part 2: Overcoring methods', International Journal of Rock Mechanics \& Mining Sciences, vol. 40, pp. 999-1010.

Sjöberg, J, Dahnér, C, Malmgren, L \& Perman, F 2011, Forensic analysis of a rock burst event at the Kiirunavaara Mine-results and implications for the future', in D Sainsbury, R Hart, C Detournay \& M Nelson (eds), Proceedings of the 2nd International FLAC/DEM Symposium, Itasca International Inc., Melbourne, pp. 67-74. 
